\title{
The Innovation Research of Management Mode for Army College Laboratory
}

\author{
Baichun Yang ${ }^{1, a}$, Guangsheng Jing ${ }^{2, b}$ and Jianhui Wei ${ }^{3, c}$ \\ ${ }^{1,2,3}$ Changchun engineering technology college, Changchun, 130117, China \\ a,b,c email: 25263820@163.com
}

Keywords: The army colleges; laboratory ;management mode; innovation research.

\begin{abstract}
As a complete laboratory practice teaching platform of military colleges, how to optimize the internal management, is the important topic in front of each army colleges and universities. Military colleges and universities from the current existing problems in laboratory construction and laboratory management, analyses the reasons of the existence, and proposes the corresponding management measures, has strong practical significance.
\end{abstract}

\section{Introduction}

Major military academies and schools to foster "vocational, applied and compound" talent training goal, the goal lies in how to reasonable training objectives into specific, strong operability of training scheme and the safeguard measures. And practical teaching is the important way to achieve this goal, the quality of the practical teaching is directly related to the quality of talent training, military academies and schools as a complete laboratory practice teaching platform of military colleges, how to optimize the internal management, is the important subject in front of each army colleges and universities, management mode is the lab core and the soul of the construction of soft environment, is the fundamental problem of the work in the laboratory, the army colleges and universities to guarantee the quality of experiment teaching, we must attach great importance to the choice of laboratory management mode and innovation[1].

\section{The Main Problems of Military Colleges and Universities Laboratory Management}

\subsection{Basic copy held pattern in colleges and universities, there is no form features}

Because the army colleges history is shorter, the lack of managerial experience, in terms of people, goods, content of precipitation resources rarely, coupled with the laboratory in charge of the leadership of military academies and schools for the universities were mostly, these reasons determine the army colleges and universities laboratory system architecture and the laboratory construction, copying the mother school model only for appropriate improvement, copying the various management system is not aimed at the training target of military academies and schools, and the characteristics of the students in architecture, exists the phenomenon of water. Laboratory daily management system, capital equipment pipe system, equipment procurement system, laboratory personnel appraisal system needs to be further improved.

\subsection{Laboratory construction lack of rational planning for a long time}

Military academy professional Settings and the professional training scheme is more flexible, can according to the requirements of the society for the professional personnel to adjust, but this characteristic to bring convenient survival and development of military academies and schools at the same time to the laboratory construction of military colleges and universities has brought great difficulties, makes the laboratory planning lack of long-term and rationality. Main show is: one is some professional training scheme, especially the new professional, itself is not form a complete set of laboratory construction plan in detail, the laboratory construction is often the curriculum to the need to bring up; two it is due to the heavy task, and the impact of funds is relatively limited, the laboratory construction often trade-off problems, in order to ensure that urgently needs to use the lab 
and pay attention to the balance of each professional, some of the laboratory construction may not be in place in time; Three is no military academies and schools form their own characteristics and brand disciplines, nature also cannot be skewed construction of laboratory, unable to form the lab has a certain influence.

\section{3 laboratory construction urgent task, demanding}

To reduce running cost, at the beginning of the military academy was founded, mostly USES the Shared matrix laboratory resources of the school, only a small amount of construction and the constructive thoughts of laboratory. Laboratory construction of military academies and schools demand is very high, should not only consider the function of education, the construction of the laboratory needs to meet the requirements of applied talents of practical ability training, and funding sources of military academies and schools limited determines the laboratory construction must pay attention to the money and creating value, also have to consider the economic benefit in the construction[2].

\section{The Management Countermeasures Based on the Analysis of the Fundamental Mode}

\subsection{The principle of eliminate the army colleges and universities laboratory growth limit}

Management guru Peter Senge (Peter m. Senge) in his classic book "the fifth discipline, the art and practice of learning organization," a book points out for fundamental mode of growth limit management policy: don't go to promote the "enhanced growth loop", and to eliminate the source (or less) [3]. So when maximum growth has occurred in the system of structure, efforts to promote enhanced loop, is in doing this, you should find the reason in a negative feedback loop, find out the solution to solve the problem, eliminate the negative feedback loop of the restraining factors, make the positive feedback effect. Peter senge proposed to eliminate or reduce the negative feedback loop restricts the management policy, but did not set the principle of how to eliminate the negative feedback loop constraints.

\section{2 management countermeasures of set up to eliminate negative feedback loop}

\subsection{1 increase the support system development by Leader Supporting}

Can go out, please come in and visit more experimental teaching demonstration center at or above the provincial level, provincial center for construction performance and good laboratory in higher vocational colleges, learn the advanced management experience, broaden the work leadership vision and thinking[4]. At the same time to strengthen contact with enterprise or business unit of choose and employ persons such as the deepening leadership understanding of students' ability of practice needs to unit of choose and employ persons, and pay more attention to the laboratory work; Sense of achievement and strengthen the leadership of the laboratory construction performance and sense of responsibility, clear oneself to the implementation of the overall planning and development of the school laboratory, feel your hands of the construction of the laboratory condition. Through the above method to strive for leadership of the support, increasing laboratory system support for the development of military academies and schools, eliminate the lack of leadership support the growth of the upper limit.

\subsubsection{Eliminate internal friction force of the development of the system by disentangling the relationship between the parties}

Frame smooth out relations, reasonable layout, efficient open laboratory system is to improve the laboratory construction and management level, ensure that the key benefit of laboratory construction. It can effectively eliminate the internal friction force of the development of the system, solve the busywork due to relatively insufficient management system. To this end, the army colleges should separate establishment of laboratory management organization. Give support in personnel, adjust and clearly associated with the laboratory work of educational administration, financial, personnel, logistics, department of power and responsibility, avoid overlapping responsibilities, vacuum or unclear. At the same time, considering the particularity of military academies and schools, should be 
in institutional functions with counterpart contact with maternal school related functional departments.

\subsection{3 increase system development impetus by perfecting incentive mechanism}

Established to form a leadership, professional experiment personnel, teachers, students and school mechanism of the interests of the common objectives, Shared responsibility[5]. Get responsibility to put in place. For leadership, lab full-time staff, teachers, students' motivation. To improve laboratory staff satisfaction and experimental teachers and leaders to participate in the enthusiasm of lab work. Make them squeeze time, effort, think study on experiment teaching, experiment teaching and laboratory construction and management work, for the army strong impetus for the development of colleges and universities laboratory system.

\subsection{4 increase system development pressure by strengthen daily management}

Military colleges and universities can be aimed at building provincial experimental teaching demonstration center. According to the experimental teaching demonstration center of evaluation system and standard strengthen daily management, to establish relatively perfect laboratory regulations, laboratory staff job responsibilities, the experimental teaching management system, and measures for the management of instruments and equipment, laboratory construction demonstration system, instruments and equipment procurement rules, such as laboratory management system, to ensure that the work laws, rule-based. And strictly implement the management system in the lab daily operation, increase the evaluation of the implementation of the management system, enhance the system of the development of moderate pressure, eliminate management system and evaluation system of construction is relatively insufficient relatively insufficient growth limit.

\section{The lab of full-time staff training strategy research}

Military academy lab currently widespread (advanced) laboratory specialized personnel serious insufficient, the solution to this problem is usually has two modes, one is the expert to solve the problems with the aid of the mother school, 2 it is to take the way of self cultivation. Share the mother school resources is the insufficient military colleges and universities laboratory specialized personnel, the symptoms of the problem solution and self education is the fundamental solution of these two kinds of solutions can solve the problem, but share the mother school resources this way of solve the problem of increased dependence on maternal school experts, independent college to weaken the ability of their own talent cultivation, to form a laboratory specialized personnel problem solving context model. According to modern management guru Peter Senge (Peter Senge) puts forward management measures, in solving the problem of point model we should focus on the fundamental solution. But if the problem urgently, because the fundamental solution of the effect is affected by the behindhand time, in the process of fundamental solution, can be used temporarily symptoms for a time. So the army colleges and universities should make great efforts to cultivate their own laboratory personnel.

\subsection{Improve treatment, stability and attracting talent}

Laboratory full-time staff treatment problem is the biggest factor to affect the job satisfaction, to stabilize and attract talents working in the laboratory, college through the following ways to improve treatment, obtain good actual effect: first of all, pay and annual distribution with the same level administrative personnel are the same, although laboratory full-time staff salary and year-end distribution than with low level of teachers, but with the same level administrative personnel makes the same lab full-time staff work enthusiasm has a fundamental guarantee.

\subsection{Actively encourage and create conditions for laboratory holds the full-time staff}

Lab classes full-time staff has several big advantages, one is to reduce cost of school; Second is to improve the laboratory the actual treatment of full-time staff, full-time staff three is to make the laboratory exercise and improve their teaching ability and academic level of the platform. Four is laboratory full-time staff due to the strong ability of practice, and contact with the actual work 
precision, the content of the interpretation is more practical, accord with the training target of military academies and schools.

4.3 With the help of various events and external service work, increase its temporary income For example, some military colleges and universities laboratory full-time staff in addition to the two college staff, great majority is beginning ability is strong, cadets repeatedly won various awards. To give full play to their strengths, in the student to participate in all kinds of competitions, such as the province's electronic design competition, computer knowledge, normal school life basic skill, art show, language basic skills competition, mathematical modeling contest, and so on, all guidance teacher, ask them to do in good competition achievements at the same time also increased their temporary income. In addition, the laboratory of computer grade examination, training and other foreign service work, also increases the temporary income of laboratory full-time staff.

\subsection{With the person this, completes the laboratory work full-time staff career planning}

Career planning, career design, can also be called refers to individuals and organizations, the combination of the subjective and objective conditions of a person's career based on the study of the determination, analysis, summary, for their own interest, interest, ability, specialty and experience and insufficient and so on various aspects carries on the comprehensive analysis and weigh, combining with the characteristics of age, according to their own professional tendency, determine the best career goals, and make effective arrangements to achieve this goal. For military colleges and universities laboratory system, because of the career planning can give laboratory workers drawn - $\mathrm{N}$ the feasible development blueprint, as long as the members of the effort, organizations will provide him with a rising and development of the space, the high level of motivation is not only effective, and persistent, is advantageous to the talent and the rational allocation of human resources.

\subsection{Increase incentives, combining with the work, to carry out the scientific research work}

Professional papers on scientific research project declaration, reward and incentive measures such as scientific research project matching funds to carry out the project, and hired experts to guide and encourage laboratory combined with their own work full-time staff, earnestly carry out scientific research work.

\section{Conclusion}

This paper from the laboratory in the colleges and universities personnel training the role and status, this paper raises the research question - the army colleges and universities laboratory management pattern research, and the main problems of the current laboratory management of military academies and schools has carried on the summary, and build the army colleges and universities laboratory growth model and management countermeasures of ceiling base model for the army colleges and universities laboratory management and experimental teaching management has a certain reference significance.

\section{References}

[1] Qing Ceng. University laboratory management mode innovation problem study [J]. Journal of theoretical issue, 2007, (8) : 83-85.

[2] Shaofei Yang, Weimin $\mathrm{Xu}$. The United States national laboratory management mode analysis[J].Experimental technology and management, 2005, (5), 119-122.

[3] Dong Lei.The United States national laboratory management mode and its significance [J]. Journal of changsha civil administration professional technology institute, 2009, (1) : 108-110.

[4]Wei Zhu, Xiaoyan Song. China and the United States national laboratory management mode discuss [J]. Science and technology of China BBS, 2006, (1) : 27-28.

[5] Senge, P. M. , “The fifth discipline: the art and practice of the learning organization" New York, etc. Doubleday. , 1990. 